\title{
A Highly Efficient Recombineering-Based Method for Generating Conditional Knockout Mutations
}

\author{
Pentao Liu, Nancy A. Jenkins, and Neal G. Copeland ${ }^{1}$ \\ Mouse Cancer Genetics Program, Center for Cancer Research, National Cancer Institute, Frederick, Maryland 21702, USA
}

\begin{abstract}
Phage-based Escherichia coli homologous recombination systems have recently been developed that now make it possible to subclone or modify DNA cloned into plasmids, BACs, or PACs without the need for restriction enzymes or DNA ligases. This new form of chromosome engineering, termed recombineering, has many different uses for functional genomic studies. Here we describe a new recombineering-based method for generating conditional mouse knockout (cko) mutations. This method uses homologous recombination mediated by the $\lambda$ phage Red proteins, to subclone DNA from BACs into high-copy plasmids by gap repair, and together with Cre or Flpe recombinases, to introduce IoxP or FRT sites into the subcloned DNA. Unlike other methods that use short 45-55-bp regions of homology for recombineering, our method uses much longer regions of homology. We also make use of several new E. coli strains, in which the proteins required for recombination are expressed from a defective temperature-sensitive $\lambda$ prophage, and the Cre or Flpe recombinases from an arabinose-inducible promoter. We also describe two new Neo selection cassettes that work well in both $E$. coli and mouse ES cells. Our method is fast, efficient, and reliable and makes it possible to generate cko-targeting vectors in less than $2 \mathrm{wk}$. This method should also facilitate the generation of knock-in mutations and transgene constructs, as well as expedite the analysis of regulatory elements and functional domains in or near genes.
\end{abstract}

The ability to introduce virtually any mutation into the mouse genome following gene targeting in mouse embryonic stem (ES) cells provides a powerful approach for elucidating gene function in the whole animal. In many cases, however, the complete deficiency of a gene leads to embryonic lethality, precluding the analysis of gene function in later developmental stages or in the adult. This problem can be overcome by making conditional knockout mice (cko mice), which allows a gene to be inactivated in a tissue- or temporal-specific fashion (Nagy 2000). Typically, a cko allele is made by inserting loxP sites into two introns of a gene or at the opposite ends of a gene. Expression of Cre recombinase in mice carrying the cko allele catalyzes recombination between the loxp sites and inactivates the gene. By expressing Cre recombinase from a tissue-specific promoter, the gene can be inactivated in a celltype-specific fashion. The timing of Cre expression can also be controlled using inducible Cre expression systems (Hayashi and McMahon 2002) or viral delivery systems such as adenovirus or lentivirus (Shibata et al. 1997; Pfeifer et al. 2001), which makes it possible to inactivate a gene in a temporalspecific fashion.

A major limitation for generating cko mice is the difficulty and time it takes to make a cko-targeting vector. The conventional approach is to find appropriate restriction enzyme sites that are located in or near the gene. These sites are then used to ligate together loxP sites and various other DNA fragments such as homology arms, a positive selection marker such as $P G K N e o$, and a negative selection marker such as MC1TK. The problem with this approach is that restriction sites are not always located in convenient places, and this can severely limit where loxP sites are placed. A newer and much simpler approach makes use of homologous recombination to

\section{'Corresponding author.}

E-MAIL copeland@ncifcrf.gov; FAX (301) 846-6666.

Article and publication are at http://www.genome.org/cgi/doi/10.1101/ gr.749203. construct the targeting vector. This new form of chromosome engineering, termed recombineering (Copeland et al. 2001; Muyrers et al. 2001), makes it possible to introduce loxP sites and selectable markers anywhere in a gene, and greatly shortens the time it takes to make a targeting vector. Originally, recombineering was done in yeast (Baudin et al. 1993). However, during the past couple of years, it has also become possible to perform recombineering in Escherichia coli. Bacteria offer a number of advantages over yeast for recombineering. For example, manipulating recombinant DNA produced in yeast is laborious and the recombinant DNA usually has to be transferred to $E$. coli for subsequent manipulation. On the other hand, recombinant DNA produced in E. coli can be used directly, eliminating the need for DNA transfer.

Efficient homologous recombination in E. coli is made possible by the use of phage-encoded proteins, such as those encoded by the Red genes of bacteriophage $\lambda$, which permits linear double-strand DNA (dsDNA) fragments (i.e., those carrying loxP sites and selection markers) to be inserted into DNA cloned on plasmids, BACs, or PACs via homologous recombination (Zhang et al. 1998; Muyrers et al. 1999; Datsenko and Wanner 2000; Murphy et al. 2000; Yu et al. 2000; Lee et al. 2001; Swaminathan et al. 2001). Only two Red genes are required for the recombination: exo, which encodes a $5^{\prime}-3^{\prime}$ exonuclease (Exo) that acts on the $5^{\prime}$ ends of the linear dsDNA fragment to produce 3' single-strand DNA (ssDNA) overhangs, and bet, which encodes a pairing protein (Beta) that binds to the 3' ssDNA overhangs created by Exo and promotes annealing to its complementary DNA strand on the cloned DNA (Stahl 1998; Poteete 2001). The recombination functions of Exo and Beta are further assisted by $\lambda$-encoded Gam protein, which inhibits the RecBCD exonuclease activity of $E$. coli. Unlike in yeast, linear dsDNA is unstable in $E$. coli because of the activity of RecBCD. The $\lambda$ recombination functions can be expressed from a plasmid (Zhang et al. 1998; Murphy et al. 2000), or from a defective prophage integrated into the E. coli 
chromosome (Yu et al. 2000; Lee et al. 2001). In the defective prophage expression system, the recombination genes are expressed from the strong $\lambda P_{L}$ promoter, which itself is under the control of the temperature-sensitive $\lambda$ cI857 repressor. At $32^{\circ} \mathrm{C}$, expression of exo, bet, and gam is undetectable. However, by shifting the culture temperature to $42^{\circ} \mathrm{C}$ for as little as 10-15 min, expression of exo, bet, and gam can be induced to very high levels.

Here, we describe a fast, efficient, and highly reproducible method for constructing cko-targeting vectors using $E$. coli recombineering, and demonstrate the utility of this method by using it to make a cko-targeting vector for Evi9. Evi9 encodes a zinc finger transcription factor that is mutated in mouse and human hematopoietic tumors (Nakamura et al. 2000; Satterwhite et al. 2001). The ability to rapidly produce cko-knockout targeting vectors should greatly facilitate studies of gene function in the post-genome era.

\section{RESULTS}

Conditional knockout (cko) targeting vectors can be made by using recombineering to introduce loxP sites, and positive and negative selection markers, into BAC DNA by homologous recombination. The region of the $\mathrm{BAC}$ containing the loxP sites and positive and negative selection markers is then excised from the BAC and transformed into ES cells. The introduction of loxp sites into BACs is complicated, however, because most BAC vector backbones carry lox sites. These sites must be removed before any further lox sites are introduced into the BAC DNA. Additionally, BAC integrity needs to be examined after each modification, and this is difficult when the BAC inserts are large. By subcloning a 10-15-kb fragment of BAC DNA into a high-copy plasmid vector such as pBluescript $\left(\mathrm{pSK}^{+}\right)$before the lox sites are introduced, these problems can be eliminated.

\section{Subcloning DNA Via GAP Repair}

Homologous recombination via a process known as gap repair provides a convenient method for subcloning DNA from BACs into pBluescript. The gap repair method used previously for subcloning BAC DNA is shown in Figure 1. Here, the linearized pBluescript vector used for gap repair is generated by PCR amplification using two chimeric primers (Zhang et al. 2000; Lee et al. 2001). The 5' 50 nt of each primer is homologous to the two ends of the BAC sequence to be subcloned, whereas the 3' $20 \mathrm{nt}$ of each primer is homologous to pBluescript DNA. The linearized, PCR-amplified pBluescript vector is electroporated into E. coli cells induced for exo, bet, and gam expression, and which carry the BAC. Homologous recombination between the BAC DNA and the linearized pBluescript vector generates a circular plasmid that can replicate in E. coli. Ampicillin resistance $\left(A m p^{r}\right)$ can be used to select these circular products (Fig. 1).

To make subcloning by GAP repair possible, a BAC must be first transferred from its strain of origin (DH10B) into an $E$. coli strain that contains exo, bet, and gam. In our experiments, BACs are transferred into EL350 E. coli cells (Lee et al. 2001). We previously made EL350 cells by constructing a defective $\lambda$ prophage in DH10B cells, to create DY380 cells (Lee et al. 2001), because DH10B is one of the few E. coli strains known that can be efficiently transformed with BAC DNA. A cre gene under the control of the arabinose-inducible promoter, $P_{\mathrm{BAD}}$, was then introduced into the defective prophage carried in DY380 cells, to produce EL350 cells (Lee et al. 2001). In EL350

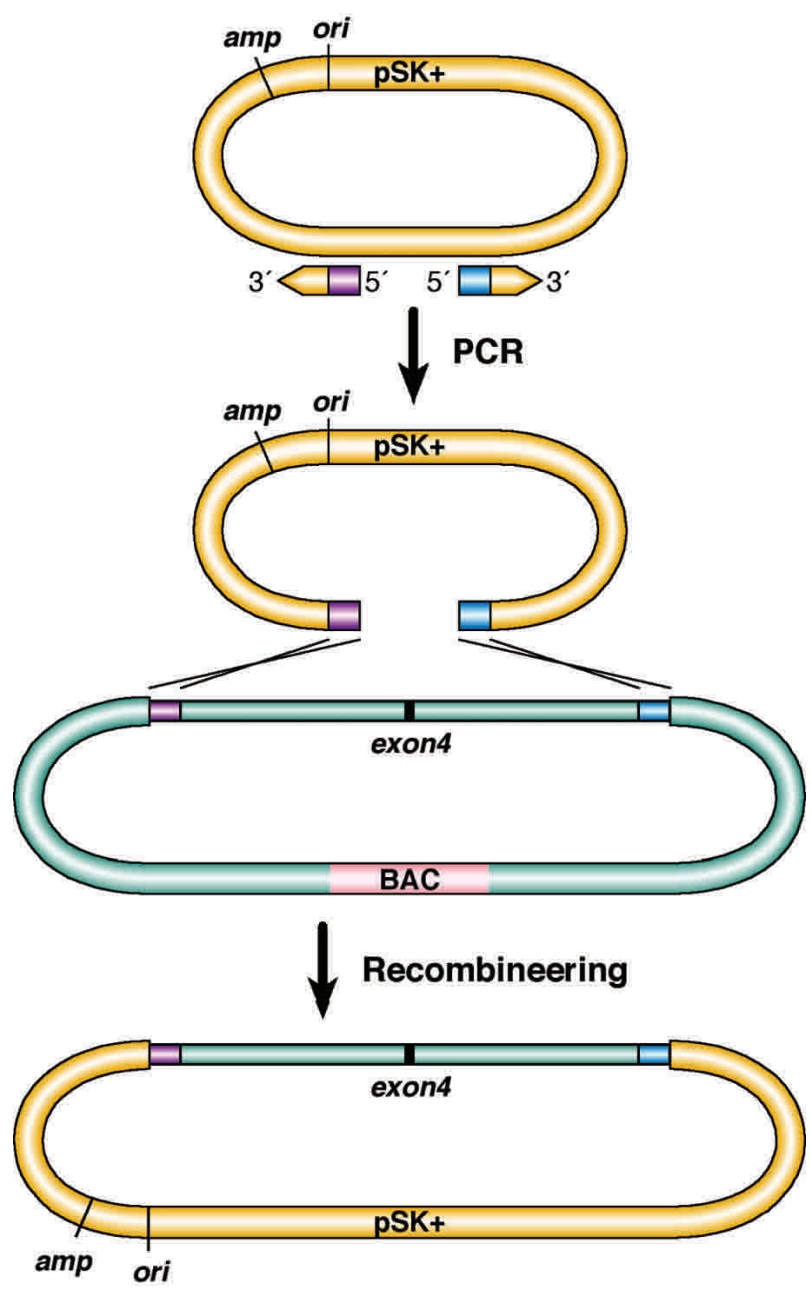

Figure 1 Subcloning a DNA fragment from a BAC into pBluescript $\left(\mathrm{pSK}^{+}\right)$by gap repair with short homology arms via recombineering. Primers that have $20 \mathrm{bp}$ of homology (yellow arrows) to pBluescript (yellow circle) at their $3^{\prime}$ end, and 50 bp (purple or blue) of homology at their $5^{\prime}$ ends to one of two ends of the BAC DNA to be subcloned (light blue), are used to amplify pBluescript. The PCR-amplified, linearized pBluescript containing the two homology arms is then transformed into recombination-competent cells that carry the BAC (BAC backbone in pink color). Gap-repaired plasmids are selected by their ampicillin resistance. The black bar denotes the location of Evi9 exon 4.

cells, the homologous recombination functions encoded by the red genes can be controlled by temperature, whereas the cre gene can be controlled by arabinose. We have also found that it is much easier to transform electro-competent EL350 or DY380 cells produced from overnight cultures, than from exponentially growing cells. When BAC DNA is electroporated into stationary electro-competent cells and the BACcontaining cells are selected using the chloramphenicol resistance $\left(\mathrm{Cam}^{\mathrm{r}}\right)$ gene that is carried in the BAC vector backbone, we routinely obtain 100 to $1000 \mathrm{Cam}^{\mathrm{r}}$ colonies from $50 \mathrm{ng}$ of BAC DNA, and virtually all of the colonies contain unrearranged BACs (data not shown). A complete list of the reagents used in these studies can be found in Table 1.

When we used the gap repair method that uses short homology (50 bp) to subclone an 11.0-kb fragment of Evi9 
Table 1. Recombineering Reagents

\begin{tabular}{|c|c|}
\hline Strains & Genotype \\
\hline $\mathrm{DH} 10 \mathrm{~B}$ & $\begin{array}{l}\mathrm{F}^{-} \text {mcrA } \Delta(\text { mrr-hsdRMS-mcrBC) } \\
\varnothing 80 \text { dlacZ } \mathrm{M} 15 \Delta \text { lacX74 deoR recA1 } \\
\text { endA1 araD139 } \Delta(\text { ara, leu }) 7649 \\
\text { ga/U ga/K rspL nupG }\end{array}$ \\
\hline DY380 & DH10B $[\lambda$ cl857 (cro-bio $A<>$ tet $]$ \\
\hline EL250 & $\mathrm{DH} 10 \mathrm{~B}\left[\lambda \mathrm{cl} 857\right.$ (cro-bioA $<>$ araC- $\mathrm{P}_{\mathrm{BAD}}$ flpe $]$ \\
\hline EL350 & $\mathrm{DH} 10 \mathrm{~B}\left[\lambda \mathrm{cl} 857\left(\right.\right.$ cro-bioA $<>$ araC- $\left.P_{\mathrm{BAD}} c r e\right]$ \\
\hline \multicolumn{2}{|c|}{ Selection cassettes } \\
\hline PL451 & FRT-PGK-EM7-NeobpA-FRT-loxP \\
\hline PL452 & IoxP-PGK-EM7-NeobpA-IoxP \\
\hline \multicolumn{2}{|c|}{ Other plasmids } \\
\hline $\mathrm{pSK}^{+}$ & pBluescript \\
\hline PL253 & Modified MC1TK \\
\hline
\end{tabular}

spanning exon 4 , we found that we were unable to obtain consistent results (data now shown). Besides a low retrieving efficiency, aberrant products were frequently obtained. Successful retrieval experiments have been reported using short homology (Zhang et al. 2000; Lee et al. 2001); therefore, our failure may be caused, in part, by the nature of the homologous sequences in our experiment. Short regions of homology, such as those used here, might have similar sequences in other regions of the BAC, and this could lead to the generation of unwanted products. Moreover, the GC content of short homology regions can influence homologous recombination as reported in yeast (Gray and Honigberg 2001). Alternatively, even though Gam is expressed and inhibits RecBCD, inhibition is likely to be incomplete, and this residual activity, or alternatively, the exonuclease activity of RecQ and RecJ, could degrade these short homology regions and make the recombination inefficient (Courcelle and Hanawalt 1999).

Because of these difficulties, we turned to an alternative method for generating gap-repaired plasmids that makes use of longer homology arms (200-500 bp; Fig. 2). As shown below, these larger homology arms significantly increase the frequency of subcloning by gap repair, and because of this, unwanted recombination products were rare. Another advantage of this alternative method is that the gap repair plasmid is not PCR-amplified, which eliminates potential artifacts introduced into the plasmid by PCR. In this alternative method, two sets of PCR primers were produced and used to amplify two 200-500-bp regions of the BAC (primers A and B and Y and Z; Fig. 2). Ultimately these two regions will mark the ends of the fragment to be subcloned by gap repair. The PCR products were purified using spin columns and digested with either NotI and HindIII or HindIII and SpeI. Restriction sites for these enzymes were included in the amplification primers to permit directional cloning of the PCR products into pBluescript. The digested fragments were again purified and ligated to NotI- and SpeI-cut pBluescript DNA that also has a TK (MC1TK) gene for use in negative selection in ES cells. The retrieval vector was subsequently linearized with HindIII to create a DNA double-strand break for gap repair.

When we electroporated $1 \mu \mathrm{L}$ (50-100 $\mathrm{ng}$ ) of the linear gap repair plasmid into electro-competent EL350 cells, which contained Evi9 BAC A12, and which had been induced for exo, bet, and gam expression by prior growth at $42^{\circ} \mathrm{C}$ for $15 \mathrm{~min}$ (Fig. 2), we found that we were able to routinely generate several thousand $\mathrm{Amp}^{\mathrm{r}}$ colonies in a single electroporation experiment. About $5 \%$ of these $\mathrm{Amp}^{\mathrm{r}}$ colonies were background colonies derived either from self-ligation of the linearized gap repair plasmid or from uncut DNA (data not shown). The other $95 \%$ of the colonies contained gaprepaired plasmids with the expected genomic inserts (Fig. 3B, lane 1).

During the gap repair process, RecBCD is inhibited by Gam so that the linear gap repair plasmid is stable. However, in the absence of RecBCD, ColE1-derivative plasmids such as pBluescript can replicate by rolling circle replication. This type of replication will eventually convert the plasmid monomers into plasmid multimers (Feiss et al. 1982). As a result, huge plasmid complexes are produced in RecBCD-deficient cells. To select against these plasmid multimers following gap repair, a small amount of the gap-repaired plasmid DNA (1 $\mathrm{ng}$ ) was retransformed into wild-type DH10B cells, and $\mathrm{Amp}^{\mathrm{r}}$ colonies were selected. Empirically, we determined that retransformation selects for plasmid monomers and eliminates plasmid multimers.

\section{Targeting the First loxP Site Into the Subcloned Plasmid DNA}

The next step in creating a cko-targeting vector is the introduction of a loxp site into the subcloned DNA: in this case, 5 ' of Evi9 exon 4 (Fig. 3A). This is accomplished by introducing a floxed neomycin resistance (Neo) cassette (PL452) via homologous recombination into the subcloned plasmid DNA, and by removing the Neo gene via Cre recombinase. The floxed Neo gene in PL452 is expressed from a hybrid PGKEM7 promoter. PGK permits efficient Neo expression in mammalian cells, whereas EM7 allows Neo to be expressed in bacterial cells. Subsequent removal of the floxed Neo gene via Cre recombinase leaves behind a single lox $\mathrm{P}$ site at the targeted locus. To introduce a floxed Neo gene at the correct location, it is first flanked with 100-300-bp arms that are homologous to the targeting site. These homology arms, as described above, are generated by PCR amplification of the BAC DNA. In this case, the PCR primer pairs were engineered to contain NotI and EcoRI (primers C and D) or BamHI and SalI (primers $\mathrm{E}$ and $\mathrm{F}$ ) restriction sites (Fig. 2). These restriction sites allow for the directional cloning of the homology arms, and the floxed Neo gene, into pBluescript. Primer D also contains a BglII site internal to the EcoRI site. The BglII site marks the presence of the lox $\mathrm{P}$ site at the targeted locus following recombination in ES cells (see below). An EcoRV site was also incorporated into primer $\mathrm{G}$ for 3 ' side diagnosis of the targeting in ES cells (see below). Following PCR amplification, the products were purified, restriction digested, and ligated to the floxed Neo cassette excised from PL452 with EcoRI and BamHI, and to pBluescript that was linearized by NotI and SalI digestion (Fig. 2). Four to six colonies selected by their kanamycin resistance, conferred by Neo, were picked and checked by restriction enzyme digestion to ensure that they were properly constructed. Usually, all of the $\mathrm{Kan}^{\mathrm{r}}$ colonies were properly constructed (data not shown). This plasmid was referred to as the minitargeting vector. The floxed Neo gene, together with the homology arms, was excised from pBluescript by NotI and SalI digestion, and gel-purified. The purified Neo cassette (150 ng) was coelectroporated along with the gap-repaired subcloned DNA (PL441, 10 ng) into EL350 cells, which had been induced for Red recombination functions by prior growth at $42^{\circ} \mathrm{C}$ for $15 \mathrm{~min}$, and frozen at $-80^{\circ} \mathrm{C}$. Transformants were selected on kanamycin plates. 


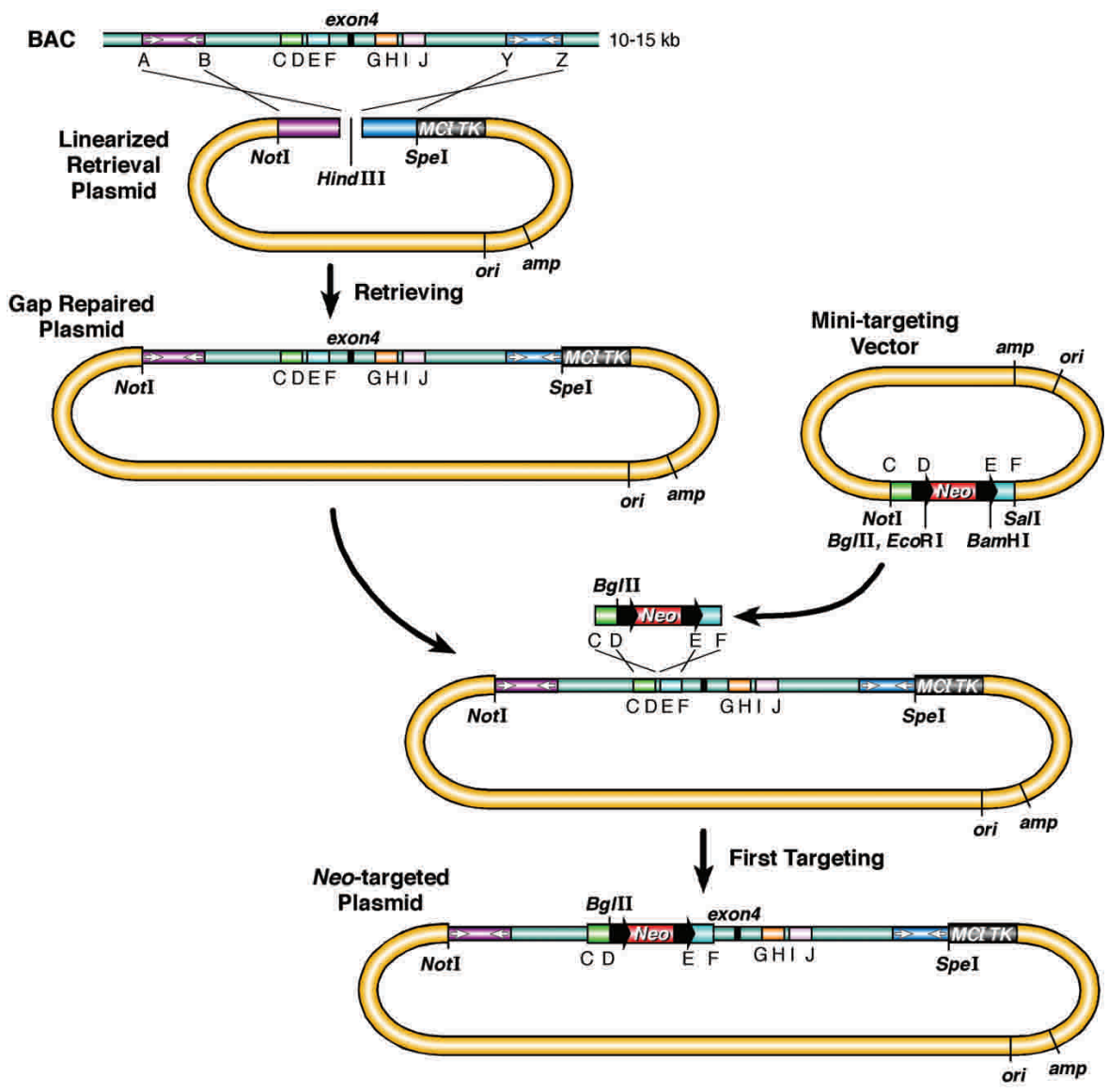

Figure 2 An improved procedure for subcloning DNA from BACs and for constructing cko-targeting vectors. The homology arms used for gap repair (subcloning) and for targeting, are PCR-amplified from BAC DNA. The two homology arms (purple or dark blue), amplified using primers A and B or primers $\mathrm{Y}$ and $\mathrm{Z}$, were cloned into an MC1TK-containing plasmid, to generate the gap repair (retrieval) plasmid for subcloning. The gap repair plasmid was linearized with Hindlll to create a DNA double-strand break for gap repair. A minitargeting vector was constructed by ligating together the two PCR products generated by amplification of BAC DNA with primers $C$ and D (light green) or primers $E$ and F (blue) a floxed Neo selection cassette (black arrow: loxP site), and pBluescript. A Bglll restriction site was included in the minitargeting vector for diagnosing gene targeting in ES cells. The black arrows denote loxP sites. The targeting cassette was excised by Notl and Sall digestion, or by PCR amplification, using primers $\mathrm{C}$ and $\mathrm{F}$. The gap-repaired plasmid and the excised targeting cassette were cotransformed into recombination-competent DY380 or EL350 cells. The recombinants had a floxed Neo cassette inserted between primers $\mathrm{D}$ and $\mathrm{E}$ and can be selected on kanamycin plates. The Neo cassette was excised with Cre recombinase, leaving a single loxP site at the targeted locus (see Fig. 3). Similarly, a Neo selection cassette can be inserted between primers $\mathrm{H}$ and I using homology arms amplified by primers $\mathrm{G}, \mathrm{H}$ (light orange), and I, J (light purple).

In one experiment, $84 \mathrm{Kan}^{\mathrm{r}}$ colonies were obtained following electroporation of induced EL350 cells, whereas only six colonies were obtained from uninduced cells. All of the six colonies were identical to the original minitargeting vector, indicating that they represented uncut plasmid. Plasmids from six of the $\mathrm{Kan}^{\mathrm{r}}$ colonies from induced EL350 cells were examined by restriction enzyme digestion to make sure they were the correct recombinants. All six colonies gave the expected restriction patterns (Fig. 3B, lane 2; data not shown).

Not all plasmids in a $\operatorname{Kan}^{\mathrm{r}}$ cell will carry the Neo cassette. This is especially true for high-copy plasmids such as pBluescript because one recombinant plasmid molecule will render the cell $\mathrm{Kan}^{\mathrm{r}}$. The cells will therefore carry mixtures of targeted and nontargeted plasmids following recombination. This problem can be reduced if only a small amount of the gap-repaired subcloned plasmid DNA (1 ng) is used for coelectroporation. Alternatively, the mixed plasmids can be retransformed into DH10B cells and grown on kanamycin plates. Because most transformed cells will only receive one plasmid, growth of the transformed cells on kanamycin plates will select against cells that receive nontargeted plasmids, and the surviving colonies will carry pure populations of targeted plasmids.

Excision of the Neo cassette from the subcloned DNA was accomplished by electroporating the targeted plasmid DNA into EL350 cells, which had been induced for Cre expression by prior growth in arabinose-containing media for $1 \mathrm{~h}$. The electroporated cells were plated on either ampicillin or kanamycin plates. Cre-mediated recombination is highly efficient; therefore, the kanamycin plates usually do not have any colonies. Colonies from the ampicillin plates were checked for their kanamycin sensitivity and restriction digestion patterns to make sure that the floxed Neo cassette was properly excised. All $12 \mathrm{Amp}^{\mathrm{r}}$ colonies picked for analysis in this experiment were kanamycin-sensitive, and contained a single loxP site at the targeted locus (Fig. 3B, lane 3; data not shown).

\section{Targeting a Second loxP Site Downstream of Evi9 Exon 4}

The final step in the construction of the cko-targeting vector is the introduction of a second loxP into the subcloned DNA, in this case, downstream of Evi9 exon 4 (Fig. 3A). One way to accomplish this task is to again introduce a floxed Neo gene into the subcloned DNA, and then remove the floxed Neo gene via Cre recombinase, leaving behind a loxP site at the second targeted locus. This is, however, complicated by the fact that the Neo gene serves as the selectable marker for gene targeting in ES cells; therefore the Neo gene can only be removed after Neo-positive ES cells are selected and homologous recombinants are identified. Transient expression of Cre recombinase in ES cells can generate three different excision products: Two recombination products are generated by recombination between the loxP site located upstream of Evi9 exon 4 and the two loxp sites located downstream of Evi9 exon 4 that flank the Neo gene. The third, and desired recombination product, results from recombination between the two loxP sites located on either side of the Neo gene. Invariably, it seems that most recombination products are the undesired ones, and in some cases, it can be difficult to obtain ES cells that contain the desired product. Another 
A

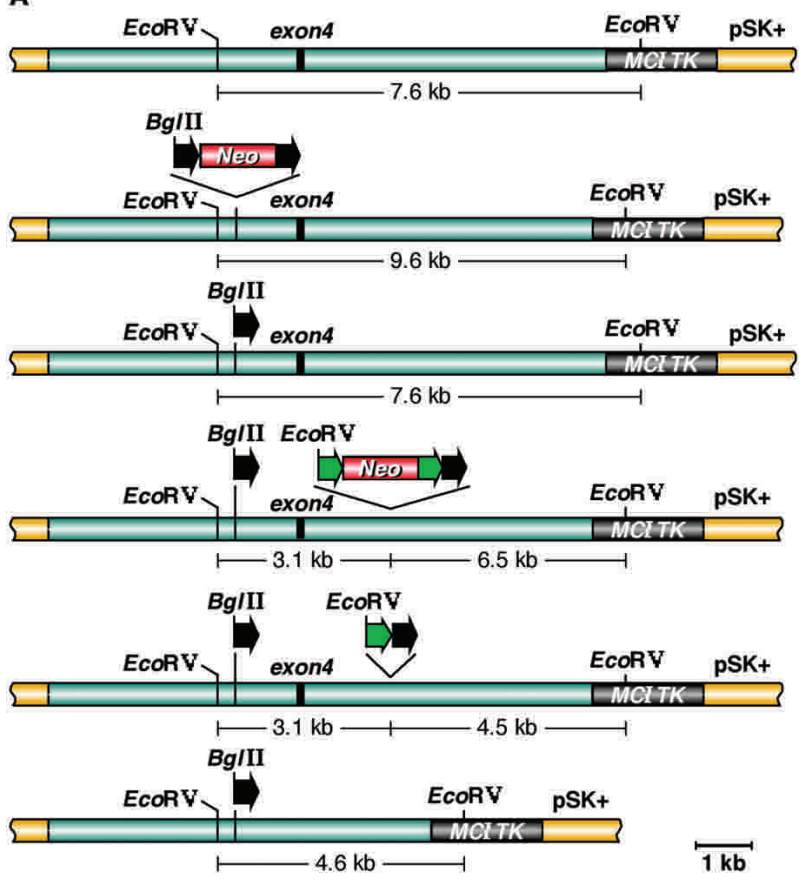

B

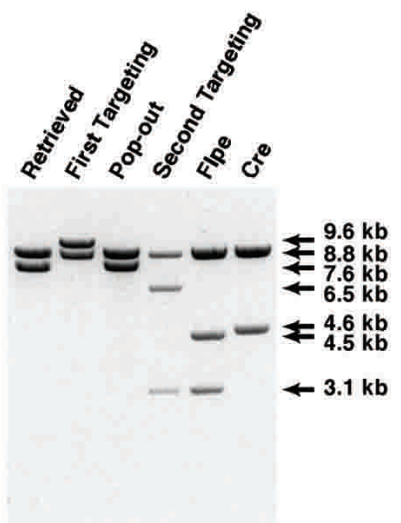

Figure 3 Constructing an Evi9 conditional knockout allele. $(A)$ The 11.0-kb genomic DNA fragment containing Evi9 exon 4 was subcloned from BAC-A12 using gap repair. EcoRV digestion of the gaprepaired plasmid generates $7.6-\mathrm{kb}$ and $8.8-\mathrm{kb}$ fragments. The $7.6-\mathrm{kb}$ fragment contains Evi9 exon 4 sequences, whereas the $8.8-\mathrm{kb}$ fragment, common to all lanes, contains plasmid sequences and Evi9 sequences located upstream of exon 4 . The floxed Neo cassette of PL452 was targeted upstream of Evi9 exon 4. In the targeted plasmid, the 7.6-kb EcoRV fragment increases in size to $9.6 \mathrm{~kb}$ because of the addition of the floxed Neo cassette. Excision of the floxed Neo cassette leaves behind a single loxP (black arrow) at the targeted locus, and the normal ECoRV digestion pattern is restored. Next, the PL451 selection cassette, containing the Neo gene flanked by FRT sites (green arrow) and a downstream loxP, was targeted downstream of Evi9 exon 4. The PL451 selection cassette contains an EcoRV site, which results in the production of $6.5-\mathrm{kb}$ and $3.1-\mathrm{kb}$ fragments following EcoRV digestion. This is the Evi9 cko-targeting vector. To test the functionality of the FRT sites in the cko-targeting vector, the PL451 selection cassette was excised from the cko-targeting vector by FLP recombinase following electroporation into EL250 cells. This reduces the size of the $6.5-\mathrm{kb}$ EcoRV fragment to $4.5 \mathrm{~kb}$. Finally, electroporation of the cko-targeting cassette into EL350 cells expressing Cre recombinase excises the entire DNA between the two loxP sites, creating a 4.6-kb EcoRV fragment. $(B)$ EcoRV-digestion patterns of the plasmids at every stage of the targeting vector construction. problem stems from the fact that the Neo gene in a previously constructed cassette (PGK-Tn5-Kan-bpA) is optimized for expression in E. coli. In our hands, we usually obtain $90 \%$ less ES colonies when we use this cassette than when we use a conventional PGKNeobpA.

To overcome these problems, we constructed a new selection cassette (PL451). PL451 was constructed by introducing an FRT site upstream of Neo, and FRT and loxP sites downstream of Neo, in PGKNeobpA, a selection cassette that is commonly used for gene targeting in ES cells (Fig. 3A). Similar to PL452, we introduced a bacterial EM7 promoter in between the PGK promoter and the coding sequence of Neo. This selection cassette works efficiently in both E. coli and mouse ES cells (data not shown). FRT is the DNA recognition site for Flp recombinase. DNA located between two FRT sites in mouse ES cells can be excised by transient expression of a genetically enhanced Flp recombinase (Flpe; Buchholz et al. 1998), which works well in ES cells. In this case, single FRT and single loxP sites were left behind at the targeted locus (Fig. 3A). Only one Flpe recombination product is possible, which ensures that all excision products are the correct ones. Alternatively, the PL451 selection cassette can be removed after the conditional allele is introduced into the mouse germ line by breeding the mice to one of the mouse strains that expresses Flpe in the mouse germ line (Rodriguez et al. 2000). Subsequent expression of Cre recombinase will excise the entire DNA between the loxP sites located on either side of Evi9 exon 4, and create an Evi9 null allele. Cre can be expressed in the mouse germ line to create a germ-line null allele, or in somatic cells.

The PL451 selection cassette was introduced into the subcloned DNA in the same manner used to introduce the floxed Neo gene upstream of Evi9 exon 4. Evi9 exon 4, including both targeted regions, was sequenced to make sure that no undesired mutations were introduced during the recombination process. To functionally test the loxP and FRT sites in the targeting vector, the cko-targeting vector plasmid DNA was transformed into arabinose-induced EL350 and EL250 cells (EL250 cells have a Flpe gene under the control of the arabinose-inducible promoter, $P_{\mathrm{BAD}}$; Lee et al. 2001), respectively. Cells were plated on ampicillin plates to select for the plasmid. Plasmid DNA was prepared and digested to confirm the expected recombination patterns (Fig. $3 \mathrm{~B}$, lanes 5,6).

\section{Gene Targeting in ES Cells}

The cko-targeting vector was subsequently linearized with NotI and electroporated into CJ7 ES cells; the transformants were selected for their G418 and ganciclovir (Ganc) resistance. Homologous recombination can occur either upstream or downstream of the loxp site located $5^{\prime}$ of Evi9 exon 4 . Because a BglII site was introduced along with the upstream loxP site, homologous recombinants carrying this loxP site (the cko allele) will generate an 18.1-kb (wild-type) and a $5.5-\mathrm{kb}$ (mutant) BglII fragment using a $5^{\prime}$ probe (Fig. $4 \mathrm{~A})$. Because we introduced an EcoRV site along with the selection cassette to the region downstream of exon 4, targeted clones will also have a $6.3-\mathrm{kb}$ EcoRV fragment detected by the 3 ' probe (Fig. 4A). In one electroporation experiment, 300 G418 ${ }^{\mathrm{r}}$ Ganc $^{\mathrm{r}}$ colonies were obtained following electroporation. Of these, 80 colonies were picked for Southern analysis, and 24 out of the 80 colonies (30\%) had the Evi9 cko allele (Fig. 4B). 


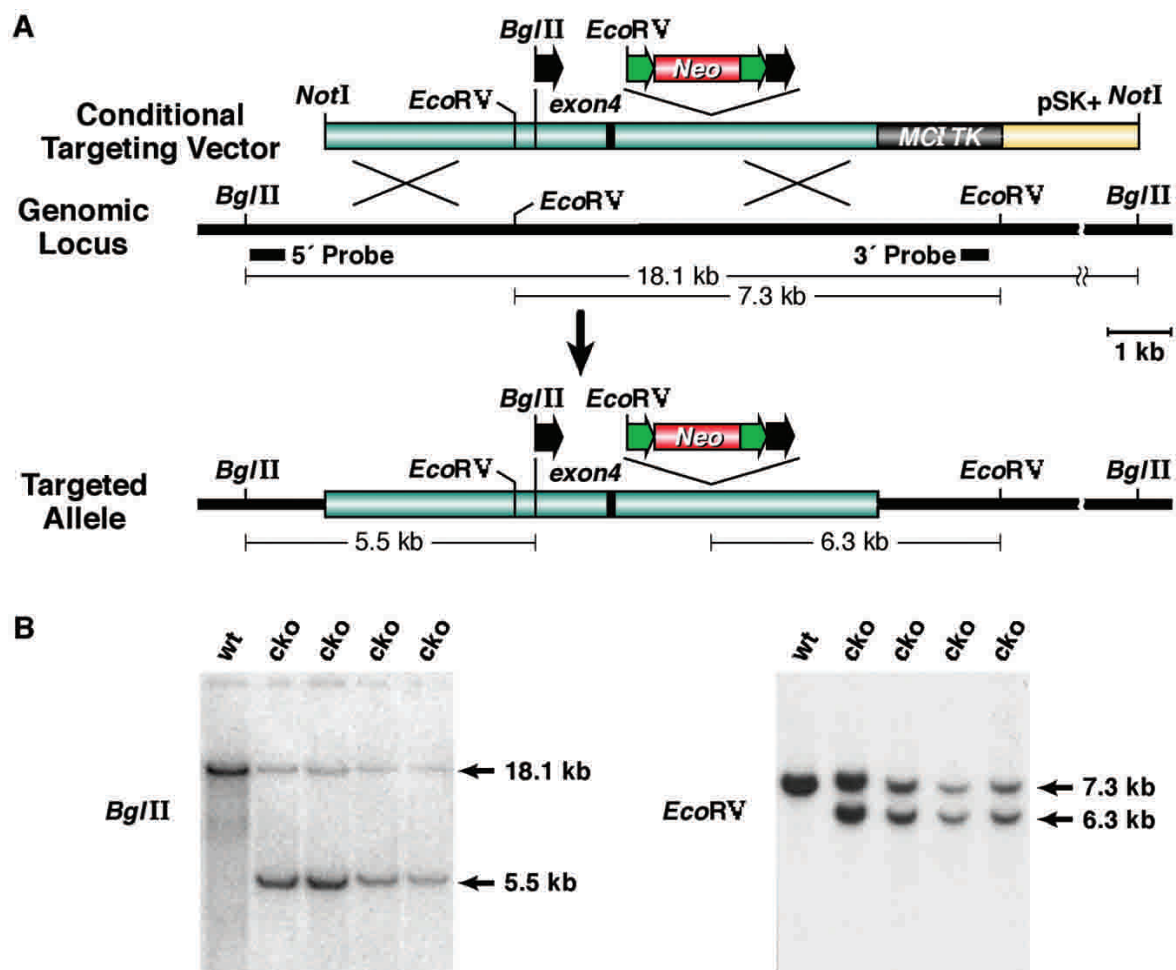

Figure 4 Identification of correctly targeted ES cell clones. $(A)$ Homologous recombination between the Evi9 cko-targeting vector and the Evi9 genomic locus. Correctly targeted ES cells (cko allele) have a 5.5-kb Bg/ll band, in addition to an 18.1-kb wild-type band, following hybridization with the $5^{\prime}$ probe. These cko clones also have a 6.3-kb EcoRV-targeted band, as well as a 7.3-kb wild-type band, following hybridization with the $3^{\prime}$ probe. (B) Southern blot analysis of the ES cell clones. The 5' probe was used in the left panel, and a $3^{\prime}$ probe was used in the right panel. (wt) Wild-type ES clones; (cko) conditional knockout ES clones.

\section{DISCUSSION}

Here, we describe a rapid and efficient method for generating cko-targeting vectors that relies on E. coli recombineering rather than restriction enzymes and DNA ligases for vector construction (Fig. 5). This method makes use of high-copy plasmids rather than BAC DNA to generate the targeting vector, 200-500 bp of homology for subcloning (gap repair), and $100-300 \mathrm{bp}$ of homology for targeting, rather than the 45-50 bp of homology used in previous experiments (Zhang et al. 1998, 2000; Yu et al. 2000; Lee et al. 2001). By using highcopy plasmid DNA for vector construction, the problem caused by lox sites present in the BAC vector backbone is eliminated, and by using longer homology arms, as many as 10,000 colonies can be obtained from a single subcloning experiment with only 50-100 ng of retrieving plasmid DNA. In addition, $>95 \%$ of the colonies are correctly constructed. This is in contrast to previous subcloning experiments using shorter regions of homology in which frequent aberrant recombinants were obtained. Moreover, using these longer homology arms, we can now routinely obtain targeting frequencies as high as $1 \times 10^{-2}$ with as little as $100 \mathrm{ng}$ of targeting DNA (i.e., targeting a floxed Neo cassette to a BAC). Similar greatly increased homologous recombination by elongated homology has been observed previously in yeast (Wach 1996).

To use high-copy plasmids such as pBluescript for vector construction, we had to modify the way we use the $\lambda$ Red system. For example, coelectroporation was used to target the floxed Neo cassette to the plasmid, instead of introducing the Neo cassette into cells that already carried the plasmid. Introduction of the $\lambda$ Red genes into cells that carry CoLE1 plasmids can cause the formation of plasmid complexes owing to rolling circle replication (Feiss et al. 1982). Cotransformation of the Neo cassette and the plasmid minimizes this problem, but still provides a high enough frequency of homologous recombination to generate the targeted plasmid. Cre-expressing EL350 cells were also used to excise the floxed Neo cassette from the targeted plasmid. When multiple plasmid molecules containing loxP sites are present in a cell expressing Cre, intermolecular recombination between the loxP sites can occur, resulting in plasmid loss. Electroporation of a small amount of plasmid DNA containing the floxed Neo cassette into Cre-expressing EL350 cells avoids this problem, yet still allows for the efficient excision of the Neo cassette. Two new selection cassettes (loxP-PGK-EM7-NeobpAloxP and FRT-PGK-EM7-NeobpAFRT-loxP) were also constructed that worked well in both $E$. coli and mouse ES cells. The second selection cassette contains two FRT sites and one loxP site that flank the selection cassette. This makes it possible to remove this selection cassette following homologous recombination in ES with Flpe recombinase, leaving behind FRT-loxP sites at the targeted locus.

When using the $\lambda$ Red system with short homology, primers and homology arms must be chosen with care. If one of the homology arms has significant sequence identity to another region of the $\mathrm{BAC}$ or plasmid, recombination is severely affected. For example, when using 45-bp homology arms, 5 bp of identical sequence between two homology arms is all that is needed to cause serious problems (Zhang et al. 2000). Longer homology arms avoid this problem. We have used 200-500-bp homology arms that contain SINE, LINE, or short DNA repeats such as CA repeats for retrieving and targeting. Efficient recombination was still achieved in all cases (data not shown). Additionally, longer homology arms can help in avoiding problems created by sequencing errors in the public databases, or strain polymorphisms. This will be especially important when modifying human DNA, where polymorphisms are much more common. With its high efficiency and reliability, more than 10 cko-targeting vectors have been constructed in our laboratory using this new method. Four of the cko-targeting vectors have been introduced into ES cells for homologous recombination. All four targeting constructs gave rise to highly efficient gene targeting frequencies in mouse ES cells: The frequency of cko alleles ranged from 20\%$40 \%$ of the $\mathrm{G} 418^{\mathrm{r}} \mathrm{Ganc}^{\mathrm{r}}$ colonies (data not shown). 


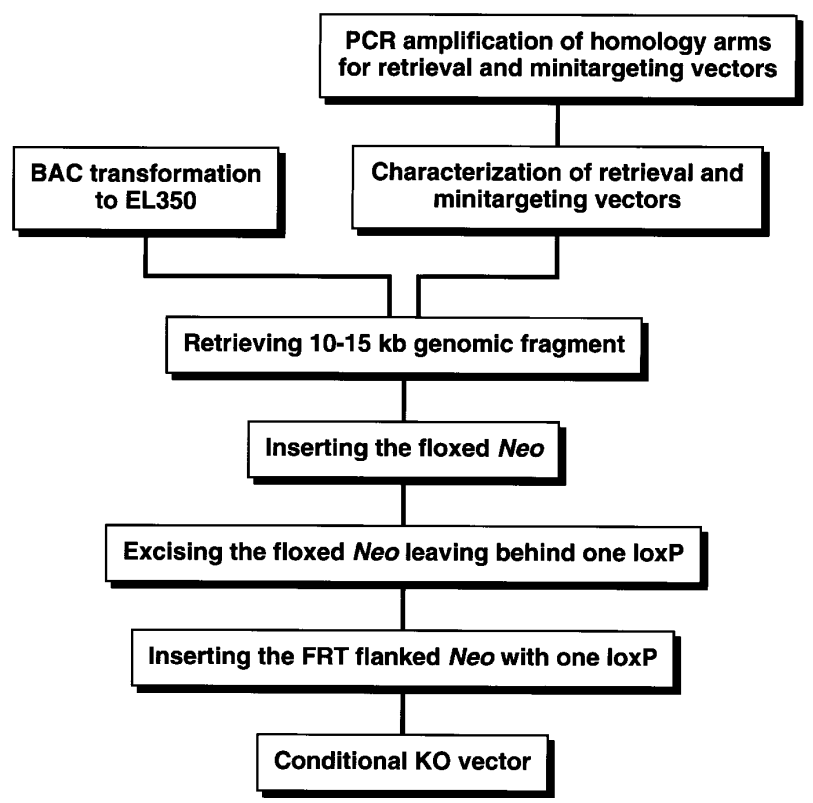

Figure 5 Flow chart showing the different steps used in making a conditional knockout targeting vector by recombineering.

The most time-consuming step in constructing the ckotargeting vector using our method is in the production of the retrieval vector and the two minitargeting vectors. However, because all of the homology arms used in the construction of these vectors are PCR-amplified from BAC DNA, only single PCR products are usually obtained, and the PCR products can thus be easily purified using spin columns. All six PCR reactions needed to construct a cko vector, including digestion of the PCR products and ligation and transformation, can be done in $1 \mathrm{~d}$. Typically, it takes less than 2 wk to construct a cko-targeting vector using this method, and multiple cko vectors can be generated simultaneously. An alternative way to generate longer homology arms for homologous recombination is by using two-step fusion PCR originally designed for enhanced homologous recombination in yeast (Wach 1996). With two-step fusion PCR, the two PCR products are amplified that serve as homology regions. Because $\sim 26$ bp of selection marker sequences are included in two of the four primers used to amplify the homology regions, one strand of each of the two PCR products can serve as the primer for amplifying the selection marker (Wach 1996).

In a recent paper (Zhang et al. 2002), a mouse genomic phage library was constructed in E. coli cells that expresses the $\lambda$ Red proteins from a plasmid. Phage clones can be isolated from this library by direct targeting of a floxed $\mathrm{Kan}^{\mathrm{r}}$ cassette flanked by 70-80-bp homology arms (Zhang et al. 2002). Such a library provides another approach for rapidly constructing cko-targeting vectors. We believe that our protocol complements this method, and offers some advantages. For example, by using BACs rather than phage libraries for vector construction, one can precisely choose a genomic region to retrieve for further manipulation. Moreover, BACs, and DNA subcloned from BACs into high-copy plasmids, can be rapidly modified using the methods described here to create knock-in mutations and transgene constructs, as well as expedite the analysis of regulatory elements and functional domains in or near genes via deletion analysis.

\section{METHODS}

\section{Bacterial Strains}

The E. coli strains used in this study are listed in Table 1. EL350 cells were derived by transferring the defective $\lambda$ prophage present in DY330 cells (Yu et al. 2000) into DH1OB cells, to create DY380 cells (Lee et al. 2001). An arabinoseinducible cre gene $\left(P_{\mathrm{BAD}}\right.$-cre) was then introduced into the defective $\lambda$ prophage present in DY380 cells to create EL350 cells (Lee et al. 2001). DH10B cells have been used to construct most BAC libraries and are highly permissive for BAC transformation, whereas DY330 cells are relatively resistant to BAC transformation. BACs were identified from the CITB BAC library constructed from CJ7 (129/Sv) ES cells (Research Genetics). DH10B electro-competent cells were purchased from Invitrogen.

\section{Construction of Retrieval and Targeting Vectors}

PCR primers were designed using MacVector. Primer sequences used for constructing the Evi9 conditional knockout vector are listed below: Primer A: NotIEvi9-ex4-Ret-5'-1, 5'ATAAGCGGCCGCTCTAATACAGAC-TGGCACCTG-3' ; Primer B: H3Evi9-ex4-ret-5'-2, 5'-GTCAAGCTTTAAAGA GATCCCTGCTATAAA-3'; Primer Y: H3Evi9-ex4-Ret-3'-1, 5' GTCAAGCTTCCTGTTTCCAGCGTAGGTGAA-3'; Primer Z: SpeIEvi9-ex4-ret-3'-2, 5'-TCTACTAGTCTCACCACCTGTA CAGTAAGT-3'; Primer C: NotIEvi9-ex4-5'L-1, 5'ATAAGCG GCCGCAACAATTAGTGTGTTTCCAGTT-3'; Primer D: EcoRIBglII-Evi9-ex4-5'L-2, 5'-GTCGAATTCAGATCTAAATGGGG TACTGAGACAAG-3'; Primer E: BamHIEvi9-ex4-5'R-1, 5' ATAGGATCCAACCAATGAGACAGTGGCACA-3'; Primer F: SalIEvi9-ex4-5'R-2, 5'-GTCGTCGCACTTATTCATGTTCCAA CAACCA-3'; Primer G: NotIEvi9-ex4-3'L-1, 5' ATAAGCGGCCGCCTTAACTTAGACAGCATGTAT-3', Primer H: EcoRI-Evi9-exon 4-3'L-2, 5'-GTCGAATTCGTCTG CAGAGGGTTAGTCAA-3'; Primer I: BamHI-Evi9-ex4-3'R-1, 5'-ATAGGATCCAGAGCAGATAGCAGTGAAAA-3'; Primer J: SalIEvi9-ex4-3'R-2, 5'-GTCGTCGCATATTACCTCACCCAAT GCTAG-3'. These primers amplify the following size fragments: 500 bp with primers A, B; $295 \mathrm{bp}$ with primers $\mathrm{Y}, \mathrm{Z}$; 222 bp with primers C, D; 276 bp with primers E, F; $277 \mathrm{bp}$ with primers $\mathrm{G}, \mathrm{H}$; and $227 \mathrm{bp}$ with primers I, J.

PCR amplification (ROCHE Expand High-Fidelity Taq kit) was performed by setting up the first reaction mixture containing $1 \mu \mathrm{L}$ of dNTP $(10 \mathrm{mM}), 1 \mu \mathrm{L}$ of DNA (10 $\mathrm{ng}$ of BAC DNA), $1 \mu \mathrm{L}(10 \mu \mathrm{M})$ of each primer, and $21 \mu \mathrm{L}$ of water. Then a second reaction mixture was set up that contained $5 \mu \mathrm{L}$ of $10 \times$ PCR buffer (\#2), $0.75 \mu \mathrm{L}$ of high-fidelity Taq $(5 \mathrm{U} / \mu \mathrm{L})$, and $20 \mu \mathrm{L}$ of water. The two reaction mixtures were then combined. PCR was performed using a PE-9700 PCR machine with the following settings: $94^{\circ} \mathrm{C}$ for $2 \mathrm{~min}$, then 10 cycles of $94^{\circ} \mathrm{C}$ for $15 \mathrm{sec}, 55^{\circ} \mathrm{C}$ for $30 \mathrm{sec}$, and $70^{\circ} \mathrm{C}$ for $1 \mathrm{~min}$. This was followed by 15 cycles of $94^{\circ} \mathrm{C}$ for $15 \mathrm{sec}, 55^{\circ} \mathrm{C}$ for $30 \mathrm{sec}, 70^{\circ} \mathrm{C}$ for $1 \mathrm{~min}$, with an additional 5 -sec extension time each cycle. To check the PCR reaction, $5 \mu \mathrm{L}$ of the $50-\mu \mathrm{L}$ PCR reaction mixture was loaded onto a gel. The remaining $45 \mu \mathrm{L}$ was mixed with $225 \mu \mathrm{L}$ of PB from QIAGEN and loaded onto a QIAGEN minipreparation spin column. After a 30-sec spin, the column was washed once with $750 \mu \mathrm{L}$ of PE buffer. The PCR fragments were eluted using $30 \mu \mathrm{L}$ of EB from QIAGEN; $3 \mu \mathrm{L}$ of restriction buffer $(10 \times)$ and $1 \mu \mathrm{L}$ of restriction enzyme was added, and the mixture was incubated at $37^{\circ} \mathrm{C}$ for $1 \mathrm{~h}$. The digested PCR fragments were purified again with the columns and were ready for ligation.

The retrieval vector was generated by mixing $3 \mu \mathrm{L}$ of PCR product 1 (left arm, NotI/HindIII), $3 \mu \mathrm{L}$ of PCR product 2 (right arm, HindIII/SpeI), $2 \mu \mathrm{L}$ of MC1TK (PL253, NotI/SpeI), $1 \mu \mathrm{L}$ of $10 \times$ ligation buffer, and $1 \mu \mathrm{L}$ of T4 DNA ligase.

The Neo-targeting vector was generated by mixing $3 \mu \mathrm{L}$ of PCR product 1 (left arm, NotI/EcoRI), $3 \mu \mathrm{L}$ of PCR product 
2 (right arm, BamHI/SalI), $2 \mu \mathrm{L}$ of floxed Neo cassette (PL452 or PL451,EcoRI/BamHI), $1 \mu \mathrm{L}$ of $\mathrm{pSK}^{+}$(NotI/SalI), $1.2 \mu \mathrm{L}$ of $10 \times$ ligation buffer, and $1 \mu \mathrm{L}$ of T4 DNA ligase. The ligation mixtures were incubated at $16^{\circ} \mathrm{C}$ for $2 \mathrm{~h}$, and $0.5 \mu \mathrm{L}$ was transformed into electro-competent DH10B cells (Invitrogen).

\section{Transformation of BAC or Plasmid DNA Into Recombinogenic Strains}

E. coli cells with BACs were grown overnight in $5 \mathrm{~mL}$ of $\mathrm{LB}$ broth with chloramphenicol. The LB broth used in our laboratory contains only $5 \mathrm{~g}$ of $\mathrm{NaCl}$ per liter. Cells were collected in three Eppendorf tubes $(2 \mathrm{~mL})$ and were resuspended in 250 $\mu \mathrm{L}$ of P1 from QIAGEN. Then $250 \mu \mathrm{L}$ of P2 and $350 \mu \mathrm{L}$ of P3 were added to each tube, and the tubes were spun for $4 \mathrm{~min}$. The supernatant fluid from these tubes was transferred to new 1.5-mL Eppendorf tubes, which were spun for another $4 \mathrm{~min}$ to clear the supernatant fluids. Finally, $750 \mu \mathrm{L}$ of isopropanol was added to precipitate the DNA (room temperature for 10 min), and the DNA was collected by spinning the tubes for 10 min at the maximal speed. The DNA pellet was washed once with $1.0 \mathrm{~mL}$ of $70 \%$ ethanol, dried, and resuspended in $50 \mu \mathrm{L}$ of TE (total from three tubes). For electroporation, $1 \mu \mathrm{L}$ of DNA was used, and for digestion $10 \mu \mathrm{L}$ (20 ng RNase was added to clear the RNA). Only freshly prepared BAC DNA was used for transformation.

EL350 or DY380 cells were grown in $5 \mathrm{~mL}$ of LB broth in a Falcon $14-\mathrm{mL}$ polypropylene round-bottom tube at $32^{\circ} \mathrm{C}$ overnight with shaking. The next day the cells $\left(\mathrm{OD}_{600}=1.2\right)$ were collected by centrifuging at $4000 \mathrm{rpm}\left(0^{\circ} \mathrm{C}\right)$ for $5 \mathrm{~min}$ in Oak Ridge tubes. Cell pellets were resuspended in $888 \mu \mathrm{L}$ of ice-cold water. Cells were transferred to a 1.5-mL Eppendorf tube (on ice) and centrifuged using a benchtop centrifuge for 15-20 sec at room temperature. The tubes were placed on ice, and the supernatant fluids were aspirated. The process was repeated two more times. Finally, the cell pellet was resuspended in $50 \mu \mathrm{L}$ of ice-cold water and transferred to a precooled electroporation cuvette (0.1-cm gap). Next $1 \mu \mathrm{L}$ of BAC DNA (100 ng) or plasmid DNA (1.0 ng) was added and mixed. Electroporation was performed using a BIO-RAD electroporator under the following condition: $1.75 \mathrm{kV}, 25 \mu \mathrm{F}$ with the pulse controller set at $200 \Omega$. The time constant was usually set at 4.0. Then $1.0 \mathrm{ml}$ of LB was added to each cuvette, which was incubated at $32^{\circ} \mathrm{C}$ for $1 \mathrm{~h}$. Cells were spread on plates with the appropriate antibiotics.

\section{Retrieving}

EL350 cells containing BAC-A12 were inoculated into $5 \mathrm{~mL}$ of LB broth in a Falcon 14-mL polypropylene round-bottom tube and grown at $32^{\circ} \mathrm{C}$ overnight with shaking. The next day, $1.0 \mathrm{~mL}$ of the overnight culture $\left(\mathrm{OD}_{600}=1.2\right)$ was transferred to $20 \mathrm{~mL}$ of $\mathrm{LB}\left(\mathrm{OD}_{600}=0.05-0.1\right)$ and incubated for 2 $\mathrm{h}$ with shaking $\left(180 \mathrm{rpm}, \mathrm{OD}_{600}=0.5\right)$. Next, $10 \mathrm{~mL}$ of the cells were transferred to a new flask and shaken in a $42^{\circ} \mathrm{C}$ water bath for $15 \mathrm{~min}$. The cells were put into wet ice and the flask was shaken to make sure that the temperature of the flask dropped as fast as possible. The flask was left in wet ice for another $5 \mathrm{~min}$. The cells were transferred to $25-\mathrm{mL}$ glass centrifuge tubes and spun at $4000 \mathrm{rpm}\left(0^{\circ} \mathrm{C}\right)$ for $5 \mathrm{~min}$ (with rubber adaptors). Cells were resuspended in $888 \mu \mathrm{L}$ of ice-cold water and transferred to a 1.5-mL Eppendorf tube (on ice) and washed three times with ice-cold water as described above. Finally, the cell pellet was resuspended in $50 \mu \mathrm{L}$ of ice-cold water, and 1-2 $\mu \mathrm{L}$ of the purified PCR or plasmid fragment was added and electroporated as described above. The retrieval vector (200-500 ng) was digested with 20 units HindIII in $30 \mu \mathrm{l}$ volume for $1-2 \mathrm{~h}$. Using excessive amounts of DNA would lead to some undigested DNA and cause severe background after transformation. 10-50 ng DNA was enough to obtain several thousand recombinant colonies.

\section{Targeting}

Frozen EL350 electro-competent cells were used for targeting in coelectroporation. The frozen cells were produced by adding a 10-mL overnight culture of EL350 (grown in two 14-mL tubes, $\mathrm{OD}_{600}=1.2$ ) to $500 \mathrm{~mL}$ of LB broth in a 2 -L flask. The culture was then placed in a waterbath shaker at $32^{\circ} \mathrm{C}$ until $\mathrm{OD}_{600}=0.5(\sim 2.0 \mathrm{~h})$. The flask was then transferred to a $42^{\circ} \mathrm{C}$ waterbath shaker and incubated for $15 \mathrm{~min}$. The flask was immediately put into an ice slurry and shaken for $5 \mathrm{~min}$ by hand to make sure the temperature dropped as fast as possible. The flask was put on ice for an additional $10 \mathrm{~min}$. Cells were collected at $4000 \mathrm{rpm}$ at $0^{\circ} \mathrm{C}$ for $5 \mathrm{~min}$ and washed three times with ice-cold water and once with cold $15 \%$ glycerol in water. Finally, cells were resuspended in $4 \mathrm{~mL}$ of ice-cold $15 \%$ glycerol in water. Then $50 \mu \mathrm{L}$ of the cells were aliquoted to precooled Eppendorf tubes (80 tubes total) and stored at $-80^{\circ} \mathrm{C}$.

For electroporation, the frozen cells were thawed at room temperature and quickly put on ice. Cotransformation of the purified targeting cassette (100 ng in $1 \mu \mathrm{L}$ of $\mathrm{EB})$ and the template plasmid DNA (10 ng in $1 \mu \mathrm{L}$ of $\mathrm{EB}$ ) was performed using a BIO-RAD electroporator as described previously. Minitargeting vector was digested with NotI and SalI to excise the targeting cassette. $500 \mathrm{ng}$ DNA was digested in $30 \mu \mathrm{l}$ volume with 20 units of NotI and SalI. Since the targeting cassette is about 2.5-3 kb in most cases, it is difficult to separate it from pBluescript backbone $(3.0 \mathrm{~kb})$. We gel-purified the cassette and the PBluescript bands together. The mixed DNA still gave rise to high targeting efficiency.

\section{Excision of the Neo Cassette}

Frozen EL350 cells induced for Cre expression by prior growth in arabinose-containing medium were used for excision of the floxed Neo cassette. A 10-mL overnight culture of EL350 cells was added to $500 \mathrm{~mL}$ of $\mathrm{LB}$ broth in a 2 -L flask. The culture was placed in a waterbath shaker at $32^{\circ} \mathrm{C}$ until $\mathrm{OD}_{600}=0.4$ $(2.0 \mathrm{~h}, 180 \mathrm{rpm})$. Then $5 \mathrm{~mL}$ of $10 \% \mathrm{~L}(+)$ arabinose (Sigma A-3256) in $\mathrm{H}_{2} \mathrm{O}$ was added to the culture to a final concentration of $0.1 \%$ and shaken at $32^{\circ} \mathrm{C}$ for another hour. Cells were collected, and cell pellets were washed and frozen as described above. Next, 1 ng of plasmid DNA was electroporated into $50 \mu \mathrm{L}$ of frozen competent cells. Then $1.0 \mathrm{~mL}$ of $\mathrm{LB}$ broth was added to the electroporation cuvette; $10-100 \mu \mathrm{L}$ of the cells were subsequently plated on an ampicillin plate and $100 \mu \mathrm{L}$ on a kanamycin plate and incubated at $32^{\circ} \mathrm{C}$ overnight. The ampicillin plate should have 10-100 colonies, and there should be no colonies on the kanamycin plate. We used the following antibiotic concentrations in our experiments: kanamycin and chloramphenicol, $12.5 \mu \mathrm{g} / \mathrm{mL}$ for BACs, 25 $\mu \mathrm{g} / \mathrm{mL}$ for multicopy plasmids; ampicillin, $25 \mu \mathrm{g} / \mathrm{mL}$ for BACs, $100 \mu \mathrm{g} / \mathrm{mL}$ for pBluescript.

\section{Gene Targeting in Mouse ES Cells}

For gene targeting, $20 \mu \mathrm{g}$ of NotI-linearized Evi9 cko-targeting vector (PL460) DNA was electroporated into $10 \times 10^{6}$ CJ7 ES cells that were growing on mitomycin-C-inactivated STO cells. Transfectants were selected in M15 medium (15\% fetal bovine serum in DMEM with $2 \mathrm{mM}$ L-glutamine) with G418 $(180 \mu \mathrm{g} / \mathrm{mL})$ and ganciclovir $(2 \mu \mathrm{M})$. Targeted clones were identified on Southern blots with the $5^{\prime}$ and $3^{\prime}$ probes.

\section{ACKNOWLEDGMENTS}

We thank Don Court and Yang Du for critical reading of this manuscript and Richard Frederickson for graphic illustration. This research was supported by the National Cancer Institute, DHHS.

The publication costs of this article were defrayed in part by payment of page charges. This article must therefore be 
Liu et al.

hereby marked "advertisement" in accordance with 18 USC section 1734 solely to indicate this fact.

\section{REFERENCES}

Baudin, A., Ozier-Kalogeropoulos, O., Denouel, A., Lacroute, F., and Cullin, C. 1993. A simple and efficient method for direct gene deletion in Saccharomyces cerevisiae. Nucleic Acids Res.

21: $3329-3330$.

Buchholz, F., Angrand, P.O., and Stewart, A.F. 1998. Improved properties of FLP recombinase evolved by cycling mutagenesis. Nat. Biotechnol. 16: 657-662.

Copeland, N.G., Jenkins, N.A., and Court, D.L. 2001. Mouse genomic technologies recombineering: A powerful new tool for mouse functional genomics. Nat. Rev. Genet. 2: 769-779.

Courcelle, J. and Hanawalt, P.C. 1999. RecQ and RecJ process blocked replication forks prior to the resumption of replication in UV-irradiated Escherichia coli. Mol. Gen. Genet. 262: 543-551.

Datsenko, K.A. and Wanner, B.L. 2000. One-step inactivation of chromosomal genes in Escherichia coli K-12 using PCR products. Proc. Natl. Acad. Sci. 97: 6640-6645.

Feiss, M., Siegele, D.A., Rudolph, C.F., and Frackman, S. 1982. Cosmid DNA packaging in vivo. Gene 17: 123-130.

Gray, M. and Honigberg, S.M. 2001. Effect of chromosomal locus, GC content and length of homology on PCR-mediated targeted gene replacement in Saccharomyces. Nucleic Acids Res. 29: $5156-5162$.

Hayashi, S. and McMahon, A.P. 2002. Efficient recombination in diverse tissues by a tamoxifen-inducible form of Cre: A tool for temporally regulated gene activation/inactivation in the mouse. Dev. Biol. 244: 305-318.

Lee, E.C., Yu, D., Martinez de Velasco, J., Tessarollo, L., Swing, D.A., Court, D.L., Jenkins, N.A., and Copeland, N.G. 2001. A highly efficient Escherichia coli-based chromosome engineering system adapted for recombinogenic targeting and subcloning of BAC DNA. Genomics 73: 56-65.

Murphy, K.C., Campellone, K.G., and Poteete, A.R. 2000. PCR-mediated gene replacement in Escherichia coli. Gene 246: 321-330.

Muyrers, J.P., Zhang, Y., Testa, G., and Stewart, A.F. 1999. Rapid modification of bacterial artificial chromosomes by ET-recombination. Nucleic Acids Res. 27: 1555-1557.

Muyrers, J.P., Zhang, Y., and Stewart, A.F. 2001. Techniques: Recombinogenic engineering-New options for cloning and manipulating DNA. Trends Biochem. Sci. 26: 325-331.

Nagy, A. 2000. Cre recombinase: The universal reagent for genome tailoring. Genesis 26: 99-109.

Nakamura, T., Yamazaki, Y., Saiki, Y., Moriyama, M., Largaespada,
D.A., Jenkins, N.A., and Copeland, N.G. 2000. Evi9 encodes a novel zinc finger protein that physically interacts with BCL6, a known human B-cell proto-oncogene product. Mol. Cell. Biol. 20: $3178-3186$.

Pfeifer, A., Brandon, E.P., Kootstra, N., Gage, F.H., and Verma, I.M. 2001. Delivery of the Cre recombinase by a self-deleting lentiviral vector: Efficient gene targeting in vivo. Proc. Natl. Acad. Sci. 98: $11450-11455$.

Poteete, A.R. 2001. What makes the bacteriophage $\lambda$ Red system useful for genetic engineering: Molecular mechanism and biological function. FEMS Microbiol. Lett. 201: 9-14.

Rodriguez, C.I., Buchholz, F., Galloway, J., Sequerra, R., Kasper, J., Ayala, R., Stewart, A.F., and Dymecki, S.M. 2000. High-efficiency deleter mice show that FLPe is an alternative to Cre-loxP. Nat. Genet. 25: 139-140.

Satterwhite, E., Sonoki, T., Willis, T.G., Harder, L., Nowak, R., Arriola, E.L., Liu, H., Price, H.P., Gesk, S., Steinemann, D., et al. 2001. The BCL11 gene family: Involvement of BCL11A in lymphoid malignancies. Blood 98: 3413-3420.

Shibata, H., Toyama, K., Shioya, H., Ito, M., Hirota, M., Hasegawa, S., Matsumoto, H., Takano, H., Akiyama, T., Toyoshima, K., et al. 1997. Rapid colorectal adenoma formation initiated by conditional targeting of the Apc gene. Science 278: 120-123.

Stahl, F.W. 1998. Recombination in phage $\lambda$ : One geneticist's historical perspective. Gene 223: 95-102.

Swaminathan, S., Ellis, H.M., Waters, L.S., Yu, D., Lee, E.C., Court, D.L., and Sharan, S.K. 2001. Rapid engineering of bacterial artificial chromosomes using oligonucleotides. Genesis 29: 14-21.

Wach, A. 1996. PCR-synthesis of marker cassettes with long flanking homology regions for gene disruptions in S. cerevisiae. Yeast 12: $259-265$.

Yu, D., Ellis, H.M., Lee, E.C., Jenkins, N.A., Copeland, N.G., and Court, D.L. 2000. An efficient recombination system for chromosome engineering in Escherichia coli. Proc. Natl. Acad. Sci. 97: 5978-5983.

Zhang, P., Li, M.Z., and Elledge, S.J. 2002. Towards genetic genome projects: Genomic library screening and gene-targeting vector construction in a single step. Nat. Genet. 30: 31-39.

Zhang, Y., Buchholz, F., Muyrers, J.P., and Stewart, A.F. 1998. A new logic for DNA engineering using recombination in Escherichia coli. Nat. Genet. 20: 123-128.

Zhang, Y., Muyrers, J.P., Testa, G., and Stewart, A.F. 2000. DNA cloning by homologous recombination in Escherichia coli. Nat. Biotechnol. 18: 1314-1317.

Received November 15, 2002; accepted in revised form December 10, 2002. 


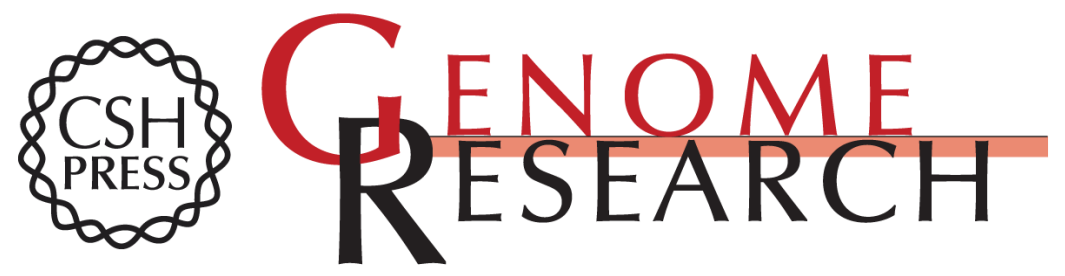

\section{A Highly Efficient Recombineering-Based Method for Generating Conditional Knockout Mutations}

Pentao Liu, Nancy A. Jenkins and Neal G. Copeland

Genome Res. 2003 13: 476-484

Access the most recent version at doi:10.1101/gr.749203

References This article cites 26 articles, 6 of which can be accessed free at:

http://genome.cshlp.org/content/13/3/476.full.html\#ref-list-1

License

Email Alerting Receive free email alerts when new articles cite this article - sign up in the box at the Service top right corner of the article or click here.

\section{Affordable, Accurate Sequencing.}

To subscribe to Genome Research go to: https://genome.cshlp.org/subscriptions 